\title{
PENGELOLAAN PERSEDIAAN PADA PT. $X$ DENGAN PERMINTAAN STOKASTIK DAN VARIABEL LEAD TIME
}

\author{
Silvi Rushanti Widodo ${ }^{1}$, Heribertus Budi Santoso ${ }^{2}$ \\ 1,2) Jurusan Teknik Industri, Universitas Kadiri \\ Email: silvi@unik-kediri.ac.id, heribertus@unik-kediri.ac.id
}

\begin{abstract}
ABSTRAK
PT. X (pemasok) merupakan suatu perusahaan manufaktur yang bergerak dibidang furniture rotan sintetik. PT. X memiliki permasalahan mengenai pengelolaan persediaan dengan distributornya (pembeli). PT. X tidak menggunakan pendekatan sistem apapun untuk mengelola persediaannya saat ini, begitu pula yang dilakukan oleh distributornya. Hal ini tentunya akan menimbulkan permasalahan pada jaringan supply chain karena setiap pelaku bisnis tersebut hanya memikirkan sistem pengelolaan persediaan yang paling menguntungkan bagi dirinya sendiri. Hal ini sangat penting karena dalam suatu jaringan supply chain, keoptimalan pasokan produk pada salah satu pihak belum tentu menjadi optimal bagi pihak yang lain. Hal ini tentunya dapat menimbulkan masalah pada biaya produksi, penentuan jumlah cadangan produk (stock), dan waktu pasokan produk dari jaringan supply chain tersebut sehingga solusi terbaik demi keuntungan bersama akan sulit tercapai. Model Joint Economic Lot Size (JELS) mengintegrasikan pengelolaan persediaan dalam supply chain, Pada model ini pemasok atau produsen akan memproduksi sesuai dengan permintaan pembeli atau konsumen dari permintaannya yang tidak menentu dan hanya berupa kisaran jumlah atau stokastik dengan mempertimbangkan variabel lead time. Perusahaan melakukan pengiriman barang sesuai dengan permintaan konsumen sehingga biaya persediaan hanya optimal bagi salah satu pihak. Besarnya penghematan yang dapat dihasilkan dari metode JELS adalah sebesar 0,51\% per tahun.
\end{abstract}

Kata kunci: Joint Economic Lot Size, Persediaan, Supply Chain.

\section{Pendahuluan}

Era globalisasi yang semakin maju mengakibatkan jumlah perusahaan semakin meningkat. Hal tersebut pun menjadikan persaingan antar setiap perusahaan semakin tinggi. Harga barang yang murah dan pelayanan yang cepat menjadi pun pilihan utama bagi setiap konsumen. Dalam menghadapi ini banyak perusahaan yang berlomba-lomba mencari strategi untuk mendapatkan harga yang kompetitif, salah satunya yaitu dengan mengendalikan persediaan barang. Tujuannya yaitu agar perusahaan dapat bertahan hidup, semakin berkembang dan memenangkan persaingan yang ada [12].

Pengelolaan persediaan tradisional hanya memandang dari satu aspek saja, yaitu pemasok ataupun pembeli. Hal ini tidak menguntung bagi kedua belah pihak karena kebijakan optimal bagi pemasok belum tentu optimal bagi pembeli. Untuk itu dilakukan sistem pengelolaan persediaan yang melibatkan semua pihak agar diperoleh nilai optimal terhadap sistem secara keseluruhan. Sistem pengelolaan tersebut dikenal dengan Manajemen Rantai Pasok [6].

Manajemen Rantai Pasok merupakan pendekatan untuk pengelolaan persediaan dan distribusi secara terintegrasi antara pemasok, produsen, distributor dan pengecer untuk meminimasi ongkos sistem secara keseluruhan [7]. Manajemen Rantai Pasok dapat dibedakan dalam tiga aspek yaitu aspek pemasok dan pembeli, aspek produksi dan distribusi, dan aspek persediaan dan distribusi [10]. Dalam pengembangan model ini, aspek yang akan dibahas adalah pemasok (produsen) dan pembeli (konsumen).

PT. X (pemasok) merupakan suatu perusahaan manufaktur yang bergerak dibidang furniture rotan sintetik. PT. X memiliki permasalahan mengenai pengelolaan persediaan dengan distributornya (pembeli). PT. X tidak menggunakan pendekatan sistem apapun untuk mengelola persediaannya saat ini, begitu pula yang dilakukan oleh distributornya. Hal ini tentunya akan menimbulkan permasalahan pada jaringan supply chain karena setiap pelaku bisnis tersebut hanya memikirkan sistem pengelolaan persediaan yang paling menguntungkan bagi dirinya sendiri. Hal ini sangat penting karena dalam suatu jaringan supply chain, keoptimalan pasokan produk pada salah satu pihak belum tentu menjadi optimal bagi pihak yang lain. Hal ini tentunya dapat menimbulkan masalah pada biaya 


\section{KAIZEN : MANAGEMENT SYSTEMS \& INDUSTRIAL ENGINEERING JOURNAL VOL. 1 NO. 1 TEKNIK INDUSTRI UNIVERSITAS PGRI MADIUN}

produksi, penentuan jumlah cadangan produk (stock), dan waktu pasokan produk dari jaringan supply chain tersebut sehingga solusi terbaik demi keuntungan bersama akan sulit tercapai.

Model persediaan seperti Joint Economic Lot Size (JELS), yang mengintegrasikan pengelolaan persediaan dalam supply chain, telah menarik perhatian beberapa peneliti untuk mengembangkannya. Model JELS pertama kali diperkenalkan 1976 [5]. Solusi yang dihasilkan dari model ini dapat memberikan penghematan yang signifikan pada total biaya persediaan gabungan. Model persediaan pemasok pembeli dengan kebijakan lot for lot dimana pemasok memproduksi tiap pengiriman ke pembeli dalam batch produksi yang terpisah [1]. Pertimbangkan kebijakan lot for lot mengalami perbaikan [4]. Pengembangkan model persediaan yang merelaksasi adanya asumsi lot for lot pada [4]. Pada model ini pemasok atau produsen akan memproduksi sesuai dengan permintaan pembeli atau konsumen dari permintaannya yang tidak menentu dan hanya berupa kisaran jumlah atau stokastik dengan mempertimbangkan variabel lead time.

\section{Metode Penelitian}

Pada model ini permintaan pada pembeli bersifat stokastik dan variasi permintaan dari pembeli diketahui oleh pemasok.Tingkat produksi pada pemasok diasumsikan tetap yaitu sebesar $\underset{p}{-}$ dimana tingkat produksi lebih besar dari tingkat permintaan $\frac{b}{p}>D$. Pembeli mengelola persediaannya dengan lead time variabel. Lead time diasumsikan sebesar jumlah lot yang diproduksi oleh pemasok dan ditambah dengan waktu delay karena transportasi, waktu non produktif, dll, yaitu sebesar $L(Q)=p Q+b$.

Pada model ini pembeli melakukan pemesanan dengan lot sebesar $n Q$ pemasok dengan biaya pesan sebesar A. Pemasok memproduksi produk dengan lot sebesar $n Q$ dengan rata-rata produksi maksimum adalah sebesar $\frac{1}{\nu}$ dan biaya setup sebesar $K$. Pembeli menerima frekuensi pengiriman sebesar $\boldsymbol{\eta}$ dengan lot pengiriman sebesar $Q$ dan biaya pengiriman sebesar $\boldsymbol{F}$ untuk setiap frekuensi pengiriman. Pembeli akan melakukan pemesanan ulang apabila pembeli memiliki on hand inventory sebesar reorder point.

Notasi yang digunakan dalam model JELS adalah:

I Rata-rata permintaan dalam satuan waktu

- Rata-rata produksi dalam satuan waktu

Frekuensi pengiriman dari pemasok kepada pembeli

I Jumlah item yang dikirim untuk setiap pengiriman dari pemasok kepada pembeli

Reorder point

Biaya setup pemasok

Biaya pesan pembeli sebesar $n Q$

Biaya transportasi / pengiriman untuk pembeli dengan setiap pengiriman sebesar $Q$

$h_{b} \quad$ Biaya simpan per unit per unit waktu untuk pembeli

$\mathrm{h}_{\mathrm{v}} \quad$ Biaya simpan per unit per unit waktu untuk pemasok

: Safety Stock

Lead time $=p Q+b$, dimana $b$ menunjukan waktu delay

Biaya stockout / biaya lost sales

Total ekspektasi biaya pembeli perunit waktu didapat dari penjumlahan biaya pemesanan, biaya pengiriman, biaya persediaan dan biaya lost sales. Total ekspektasi biaya pembeli perunit waktu ditunjukan pada rumus berikut:

$$
T C b=\left(\frac{A}{n}+F\right) \frac{Q}{\varphi}+h b\left(\frac{Q}{2}+S\right)+\frac{\pi D}{\varphi} b(s, L(Q))
$$

Dimana,

$$
b(s, L(Q))=\int_{a}^{\infty}(x-s) f(x) d x
$$

$\mathrm{x}$ adalah demand selama lead time dengan probability density function $f(x)$. Model ini menggunakan tingkat ratarata persediaan sebesar $\frac{\underline{x}}{2 Q}+$ safety stock. Sedangkan untuk total ekspektasi biaya pemasok didapat dengan mengurangi akumulasi produksi dengan akumulasi konsumsi pembeli adalah: 


\section{KAIZEN : MANAGEMENT SYSTEMS \& INDUSTRIAL ENGINEERING JOURNAL VOL. 1 NO. 1 TEKNIK INDUSTRI UNIVERSITAS PGRI MADIUN}

$$
T C V=\frac{K D}{n Q}+h v \frac{Q}{2}[n(1-D p)-1+2 D p]
$$

sehingga total biaya gabungan dapat dirumuskan sebagai:

$$
\operatorname{ETC}(Q, s, n)=\frac{Q}{U}\left(F+\frac{A+\AA}{n}+\pi b(s, L(Q))\right)+\frac{Q}{2}[h b+h v[n(1-D p)-1+2 D p]]+h b S
$$

Masalahnya adalah mencari jumlah frekuensi pengiriman $\mathrm{n}$, jumlah lot pengiriman $\mathrm{Q}$ dan juga reorder point $\mathrm{s}$, untuk meminimasi total biaya ekspetasi pada persamaan (4). Setelah itu diasumsikan juga permintaan selama lead time adalah berdistribusi normal dengan rata-rata permintaan sebesar DL(Q) dan standar deviasi sebesar $\pi \sqrt{L(Q)}$. Dalam hal ini,

$$
\begin{aligned}
& s=k \sigma \sqrt{p Q+b}, \\
& \begin{aligned}
b(s, L(Q)) & =\int_{s}^{\infty}(x-s) f(x, D L(Q)=\sigma \sqrt{L(Q)}) d x \\
& =\sigma \sqrt{p Q+b \varphi}(k),
\end{aligned}
\end{aligned}
$$

Dimana,

Dan

$$
K=\left(\frac{g-D L(Q))}{a \sqrt{L(Q)}}\right.
$$

$$
\varphi(k)=\int_{k}^{\infty}(z-k) \varnothing(z) d z
$$

Dimana $\emptyset(z)$ adalah standard normal probability density function. Karenanya, persamaan dari biaya total ekspektasi dapat ditulis sebagai

$$
\operatorname{ETC}(Q, k, n)=\frac{\varrho}{\varphi}\left(F+\frac{A+R}{n}\right)+\frac{\mathscr{Q}}{Z}(h b+h \nu\lfloor n(1-D p)-1+2 D p])+h b k \sigma \sqrt{p Q+b}+\frac{\pi \nu \sigma \sqrt{P Q+\bar{Q}}}{q} \varphi(k)
$$

Dimana $F^{\prime}(k)$ adalah sama dengan commulative density function, $F^{\prime}(k)=1-F(k)$. Nilai Q* atau nilai Q optimum didapatkan dari penurunan rumus total biaya ekspektasi (persamaan 9) terhadap nilai q.

$$
\frac{d E T Q}{\partial Q}=0
$$

Sehingga didapatkan persamaan

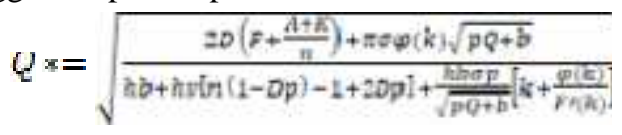

dan nilai dapat dicari dengan rumus

$$
F^{\prime}(k)=\frac{n \cdot Q Q}{\pi D+n o Q}
$$

\footnotetext{
Algoritma

Langkah 0

Langkah 1

: $\quad$ Tetapkan ETC $^{*}=\infty$ dan $\mathrm{n}=1$

Hitung nilai $\mathrm{Q}$

$: \quad Q=\sqrt{\frac{2 D\left(F+\frac{A+K}{n}\right)}{h b+h v[n(1-D p)-1+2 D p]}}$

Langkah 2

: Cari nilai k dengan persamaan (11), dan hitung nilai $\varphi(k)$

Langkah 3

Hitung nilai Q* dengan persamaan (10)

: Hitung nilai $\mathrm{s}^{*}$ dengan persamaan (5)

Langkah 4

Jika nilai $\left|Q_{*}-Q\right|=0$, hitung ETC(Q,n) dan lanjutkan ke langkah 5.

: $\quad$ Jika nilai $|Q \approx-Q|>0$, jadikan $Q \approx \rightarrow Q$ dan kembali ke langkah 2 .

Jika nilai ETC* $\geq \operatorname{ETC}(\mathrm{Q}, \mathrm{n})$ maka $\operatorname{ETC}(\mathrm{Q}, \mathrm{n}) \rightarrow \mathrm{ETC}^{*}, Q \approx \rightarrow Q$ dan $s \rightarrow \mathrm{s} *$

Langkah 5

: $\quad$ Tentukan nilai $\mathrm{n}=\mathrm{n}+1$ dan kemudian kembali ke langkah 1

Jika nilai $\mathrm{ETC}^{*} \geq \operatorname{ETC}(\mathrm{Q}, \mathrm{n})$ berhenti, maka nilai yang optimum adalah $\mathrm{n}^{*}=\mathrm{n}-1$
}

Copyright ( $)$ 2018, Kaizen : Management Systems \& Industrial Engineering Journal ISSN 15222-96806 (print), ISSN 155222-95973 (online) 


\section{KAIZEN : MANAGEMENT SYSTEMS \& INDUSTRIAL ENGINEERING JOURNAL VOL. 1 NO. 1 TEKNIK INDUSTRI UNIVERSITAS PGRI MADIUN}

\section{Hasil dan Pembahasan}

\section{Perhitungan Menggunakan Metode Saat Ini}

Metode pengendalian persediaan yang saat ini digunakan menyerupai metode Economic Production Quantity (EPQ), dimana produksi dilakukan saat persediaan telah mencapai reorder point. Jumlah produk yang diproduksi oleh pemasok adalah sebanyak jumlah produksi optimum, yaitu sebesar Q. Metode pendekatan EPQ ini digunakan karena jumlah presentase produk yang diproduksi supplier tidak diketahui. Tabel 4.1 memperlihatkan data pada pemasok yang dibutuhkan untuk perhitungan jumlah produksi optimum.

Tabel 1 Data Pemasok

\begin{tabular}{|c|c|c|c|}
\hline Notasi & Keterangan & Jumlah & Satuan \\
\hline $\mathrm{R}$ & Permintaan/tahun & 2.713 & unit/tahun \\
\hline $\mathrm{K}$ & Kapasitas produksi/ tahun & 190.800 & unit \\
\hline $\mathrm{N}$ & Hari kerja & 317 & hari/tahun \\
\hline $\mathrm{Hv}$ & Biaya simpan & $\mathrm{Rp} \mathrm{2.605,00}$ & unit/tahun \\
\hline $\mathrm{C}$ & Biaya Set up & $\mathrm{Rp} \mathrm{35.944,00}$ & /set up \\
\hline $\mathrm{L}$ & Lead time & 60 & hari \\
\hline
\end{tabular}

Dari hasil perhitungan dengan menggunakan metode EPQ maka didapatkan nilai $\mathrm{Q}=759$ unit dengan biaya total sebagai berikut:

Biaya Total $=$ Biaya Simpan + Biaya Setup $=$ Rp 1.977.195,00 + Rp 27.281.496,00 = Rp 29.258.691,00

\section{Pengendalian Persediaan Saat Ini Pada Eselon Distributor / Pembeli}

Pengendalian persediaan pada pembeli adalah dengan menggunakan metode $\mathrm{p}(\mathrm{t}, \mathrm{E})$ atau yang biasa disebut dengan metode periodic. Pemesanan ditetapkan oleh perusahaan, yaitu selama 7 hari sekali. Lead time pengiriman adalah bersifat variabel yaitu sebesar $(\mathrm{Q})=\mathrm{Pq}+\mathrm{b}$. Tabel 4.2 memperlihatkan data pada pembeli.

Tabel 2 Data Pembeli

\begin{tabular}{|c|c|c|c|}
\hline Notasi & Keterangan & Jumlah & Satuan \\
\hline $\mathrm{R}$ & Permintaan/ tahun & 2.713 & unit/tahun \\
\hline$\sigma$ & Standar deviasi permintaan & 240,38 & unit/tahun \\
\hline C. Pesan & Biaya pesan & 5.000 & $/$ pesan \\
\hline C. Transportasi & Biaya kirim/ transportasi & Rp $10.000 .000,00$ & /unit/pesan \\
\hline $\mathrm{Hb}$ & Biaya simpan & 2.605 & /unit/tahun \\
\hline $\mathrm{t}$ & Waktu/ siklus pemesanan & 0,16 & tahun \\
\hline$\pi$ & Biaya stock out/lost sales & 82.350 & $/$ unit \\
\hline $\mathrm{b}$ & Waktu delay & 0,0055 & tahun \\
\hline $\mathrm{p}$ & Kecepatan produksi & 0,000228 & \\
\hline
\end{tabular}

Dari hasil perhitungan dengan menggunakan metode periodic maka didapatkan nilai E (persediaan maksimum) adalah 53 unit dan biaya total sebagai berikut:

Biaya Total = Biaya Pesan + Biaya Simpan + Biaya Stockout + Biaya Transportasi

$$
=\operatorname{Rp} 265.000,00+\operatorname{Rp} 138.065,00+\operatorname{Rp} 4.364 .550,00+\operatorname{Rp} 53.000 .000,00=\operatorname{Rp} 57.767 .615,00
$$

Data untuk Perhitungan Metode Joint Economic Lot Size (JELS)

Data secara umum ditunjukkan oleh Tabel 3.

Tabel 3 Data Awal Keseluruhan

\begin{tabular}{|c|c|c|c|c|}
\hline No. & Keterangan & Notasi & Jumlah & Satuan \\
\hline 1 & Demand / tahun & $\mathrm{D}$ & 2.713 & unit/tahun \\
\hline 2 & Standar Deviasi & $\sigma$ & 240,38 & unit/tahun \\
\hline 3 & Biaya Pesan & $\mathrm{A}$ & 5.000 & /pesan \\
\hline 4 & Kapasitas Produksi & $\mathrm{P}$ & 190.800 & unit \\
\hline 5 & Kecepatan Produksi & $\mathrm{p}$ & 0,000228 & \\
\hline 6 & Biaya Kirim (Biaya Transportasi) & $\mathrm{F}$ & $\mathrm{Rp} 10.000 .000,00$ & /unit/pesan \\
\hline 7 & Biaya Simpan pemasok & $\mathrm{Hv}$ & 2.605 & /unit/tahun \\
\hline
\end{tabular}

Copyright (C) 2018, Kaizen : Management Systems \& Industrial Engineering Journal ISSN 15222-96806 (print), ISSN 155222-95973 (online) 


\section{KAIZEN : MANAGEMENT SYSTEMS \& INDUSTRIAL ENGINEERING JOURNAL VOL. 1 NO. 1 TEKNIK INDUSTRI UNIVERSITAS PGRI MADIUN}

Tabel 3 Data Awal Keseluruhan Lanjutan

\begin{tabular}{|c|c|c|c|c|}
\hline No. & Keterangan & Notasi & Jumlah & Satuan \\
\hline 8 & Biaya Simpan pembeli & $\mathrm{Hb}$ & 2.605 & /unit/tahun \\
\hline 9 & Biaya Stock Out / lost sales & $\pi$ & 82.350 & /unit/tahun \\
\hline 10 & Delay Time & $\mathrm{b}$ & 0.0055 & tahun \\
\hline 11 & Biaya Setup & $\mathrm{K}$ & 35.944 & /set up \\
\hline 12 & Hari Kerja & & 317 & hari/tahun \\
\hline
\end{tabular}

\section{Perhitungan Menggunakan Metode Usulan/ Metode JELS}

Perhitungan dengan menggunakan metode JELS mengintegrasikan antara pembeli dengan pemasok sehingga memiliki nilai Q yang sama dengan biaya total yang lebih kecil. Berikut adalah perhitungannya

$\mathrm{n}=1$

Langkah $0 \quad$ : $\quad$ Tetapkan ETC $*=\infty$ dan $\mathrm{n}=1$

Langkah $1 \quad$ : Hitung nilai $\mathrm{Q}$

$\mathrm{Q}=4.572,69 \sim \mathrm{Q}=4.573$ unit

Langkah $2 \quad$ : Cari nilai $\mathrm{k}$ dengan persamaan (11), dan hitung nilai $\varphi(k)$

$\mathrm{k}=0,050$ dan $\varphi(k)=0,000218$

Langkah $3 \quad$ : Hitung nilai Q* dengan persamaan (10)

Hitung nilai $\mathrm{s}^{*}$ dengan persamaan (5)

$\mathrm{Q}^{*}=4.883,3 \sim \mathrm{Q}^{*}=4.884$ unit untuk $\mathrm{s}^{*}=12,31 \sim \mathrm{s}^{*}=13$ unit

Langkah $4 \quad: \quad$ Jika nilai $\left|Q_{*}-Q \|=0 \rightarrow\right| 4.884-4.573 \mid=311>0$

Maka, $Q \approx \neg Q=4.573$ dan kembali ke langkah 2 .

Iterasi 1

Langkah 2 : Cari nilai k dengan persamaan (11), dan hitung nilai $\varphi(k)$

$\mathrm{k}=0,046$ dan $\varphi(k)=0,000114$

Langkah $3 \quad$ : Hitung nilai Q* dengan persamaan (10)

Hitung nilai $\mathrm{s}^{*}$ dengan persamaan (5)

$\mathrm{Q}^{*}=4.572,7 \sim \mathrm{Q}^{*}=4.573$ unit untuk s* $=12,31 \sim \mathrm{s}^{*}=13$ unit

Langkah $4 \quad: \quad$ Jika nilai $\left|Q_{*}-Q\|=0 \rightarrow\| 4.573-4.573\right|=0 \rightarrow 0$

$\operatorname{ETC}(4.573,1)=\operatorname{Rp} 42.425 .925,93$.

Langkah 5 $\quad: \quad$ ETC* $\geq$ ETC $(\mathrm{Q}, \mathrm{n}) \rightarrow \infty \geq \mathrm{Rp}$ 42.425.925, 93.

ETC $(\mathrm{Q}, \mathrm{n}) \rightarrow$ ETC*, Q $\rightarrow$ Q* dan s $\rightarrow \mathrm{s}^{*}$

Rp 42.425.925, 93. $\rightarrow$ ETC*, $4.573 \rightarrow Q^{*}, 13 \rightarrow \mathrm{S}^{*}$

Maka $\mathrm{n}=\mathrm{n}+1=1+1=2 \rightarrow$ kembali ke langkah 0 .

$\mathrm{n}=2$

Langkah $0 \quad$ : $\quad$ Tetapkan ETC $*$ Rp 42.425.925, 93 dan $\mathrm{n}=2$

Langkah 1 : Hitung nilai $\mathrm{Q}$

$\mathrm{Q}=1.969,7 \sim \mathrm{Q}=1.970$ unit

Langkah $2 \quad$ : Cari nilai k dengan persamaan (11), dan hitung nilai $\varphi(k)$

$\mathrm{k}=1,224$ dan $\varphi(k)=0,0053$

Langkah 3 : Hitung nilai Q* dengan persamaan (10)

Hitung nilai $\mathrm{s}^{*}$ dengan persamaan (5)

$\mathrm{Q}^{*}=1.998,1 \sim \mathrm{Q}^{*}=1.999$ unit untuk s* $=35,72 \sim \mathrm{s}^{*}=36$ unit

Langkah $4 \quad$ : Jika nilai $\mid Q_{*}-Q\|=0 \rightarrow\| 1.99 y-1.9 / 0 \|=29>0$

Maka, $Q * \rightarrow Q=1.970$ dan kembali ke langkah 2 .

Iterasi 1

Langkah 2

: Cari nilai $\mathrm{k}$ dengan persamaan (11), dan hitung nilai $\varphi(k)$

$\mathrm{k}=1,224$ dan $\varphi(k)=0,0053$

Langkah 3 : Hitung nilai Q* dengan persamaan (10)

Hitung nilai $\mathrm{s}^{*}$ dengan persamaan (5)

$\mathrm{Q}^{*}=1.998,72 \sim \mathrm{Q}^{*}=1.999$ unit untuk $\mathrm{s}^{*}=35,72 \sim \mathrm{s}^{*}=36$ unit

Langkah $4 \quad$ : Jika nilai $\|Q *-Q\|=0 \rightarrow\|1,99 y-1, y 9 y\|=0 \rightarrow 0$

$\operatorname{ETC}(1.999,2)=\operatorname{Rp} 58.564 .814,80$

Langkah $5 \quad$ : $\quad$ ETC $*<$ ETC $(\mathrm{Q}, \mathrm{n}) \rightarrow \operatorname{Rp} 42.425 .925,93<\mathrm{Rp} 58.564 .814,80$.

Copyright (C) 2018, Kaizen : Management Systems \& Industrial Engineering Journal ISSN 15222-96806 (print), ISSN $155222-95973$ (online) 


\section{KAIZEN : MANAGEMENT SYSTEMS \& INDUSTRIAL ENGINEERING JOURNAL VOL. 1 NO. 1 TEKNIK INDUSTRI UNIVERSITAS PGRI MADIUN}

Maka nilai yang optimum adalah pada $\mathrm{n}=\mathrm{n}-1=2-1=1$, yaitu pada nilai $\mathrm{Q}^{*}=4.573, \mathrm{~S}^{*}=13, \mathrm{n}=1$.

Berikut adalah hasil ringkasan biaya total antara persediaan yang terintegrasi (Menggunakan JELS) dan juga yang masih masing-masing.

Tabel 4 Rangkuman Keseluruhan

\begin{tabular}{|c|c|c|c|c|}
\hline \multirow{2}{*}{ Metode } & $\mathbf{n}$ & Supplier & DC & Total Biaya \\
\hline \multirow{2}{*}{ JELS } & 1 & - & - & $\operatorname{Rp~} 42.425 .925,93$ \\
\cline { 2 - 5 } & 2 & - & - & $\operatorname{Rp~58.564.814,80.}$ \\
\hline \multirow{2}{*}{ Masing-masing } & - & $\operatorname{Rp} 29.258 .691,00$ & $\operatorname{Rp~57.767.615,00~}$ & $\operatorname{Rp~87.026.306,00~}$ \\
\hline
\end{tabular}

Besarnya penghematan setelah menggunakan metode usulan adalah sebagai berikut

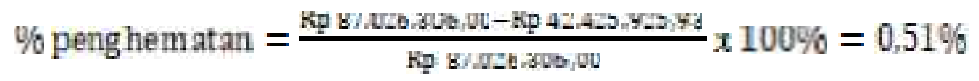

\section{Simpulan}

Kesimpulan yang dapat diambil dari penelitian ini adalah Perusahaan melakukan pengiriman barang sesuai dengan permintaan konsumen sehingga biaya persediaan hanya optimal bagi salah satu pihak. Besarnya penghematan yang dapat dihasilkan dari metode JELS adalah sebesa $0,51 \%$ per tahun

\section{Daftar Pustaka}

[1] Banerjee, A., A Joint Economic-Lot-Size Model for Purchaser and Vendor. Decision Sciences, 17, 1986, 292311.

[2] Ginting, R., Sistem Produksi, Yogyakarta, Graha Ilmu, 2007.

[3] Glock and Kim, Safety Measures in the Joint Economic Lot Size Model With Returnable Transport Items. International Journal of Production Economics, 181, 2016, 24-33.

[4] Goyal, S. K., An Integrated Inventory Model for A Single Supplier-Single Customer Problem, International Journal of Production Research, 15, 1976, 107-111.

[5] Goyal, S. K., A Joint Economic-Lot-Size Model for Purchaser and Vendor : A Comment. Decision Sciences, 19, 1988, 236-241.

[6] Jonrinaldi, S., Biaya Transportasi Tidak Linear Dalam Model Siklus Persediaan Optimal Gabungan untuk Produk yang Mengalami Deteriorasi, Jurnal Optimasi Sistem Industri, 6 (1), 2006, 59-68.

[7] Levi, D. S., and Kaminsky, P., Design and Managing the Supply Chain, Mc Graw-Hill, Singapore, 2000.

[8] Marchi and Glock, A Joint Economic Lot Size Model With Financial Collaboration and Uncertain Investment Opportunity, International Journal of Production Economics, 176, 2016, 170-182.

[9] Muller, M., Essential of Inventory Management, Amacom, USA, 2003.

[10] Ongsakul, V., Liman, S. D., Joint Economic Lot Size Problem with Pipeline Inventory Cost, Thesis, Department of Industrial Engineering, Texas Tech University, Texas, 1998.

[11] Ristono, A., Manajemen Persediaan Edisi 1, Graha Ilmu, Yogyakarta, 2009.

[12] Santoso., and Elias, Y.,. Penentuan Joint Economic Lot Size Pada Pemasok Kursi Lipat dan Pembelinya Dengan Permintaan Probabilistik dan Lead Time Varibel. Seminar Nasional IENACO, 2014.

[13] Sari, D., and Huang, L., Models of Joint Economic Lot Sizing Problem With Time-based Temporary Price Discounts, International Journal of Production Economics, 139, 2012, 145-154.

[14] Siajadi, H., Ibrahim, R. N., and Lochert, P. B., Joint Economic Lot Size in Distribution System With Multiple Shipment Policy, International Journal of Production Economics, 102 (2), 2006, 302-316. 